ISSN: 0213-2052 - eISSN: 2530-4100

DOI: http://dx.doi.org/10.14201/shha201937161183

\title{
LA REPRESENTACIÓN DE ANTINOO Y ADRIANO-ARES/MARTE EN EL CONTEXTO ARGÓLICO
}

\section{The Representation of Antinous and Hadrian-Ares/ Mars in the Argolic Context*}

\author{
Rocío GORDILLO HERVÁS \\ Universidad Pablo Olavide \\ rgorher@upo.es
}

Fecha de Recepción: 1-5-2019; aceptación definitiva: 10-6-2019

ORCID: 0000-0001-5492-3378

RESUMEN: La finalidad de este artículo es la identificación de la figura masculina del anverso de una moneda acuñada en Argos dedicada a Antinoo (RPC 3, 390) con Adriano representado con la iconografía de Ares/Marte. A tal efecto, se realizará un análisis comparativo con otra pieza monetal emitida por Argos dedicada al emperador Adriano y con tres esculturas de Marte de periodo (posiblemente) adrianeo. En segundo lugar, se indagará en la importancia que pudo tener el posible adventus de Adriano en la ciudad de Argos con motivo de la elección de Ares/Marte en su iconografía numismática.

Palabras clave: Argos; Adriano; Antinoeia; Ares; Marte; Templo de Venus y Roma; Villa Adriana.

* Este trabajo forma parte del proyecto "Adriano y la integración de la diversidad regional" (HAR2015-65451-c2-1 MINECO/FEDER). Quisiera agradecer al Profesor Michel Amandry por proporcionarme las imágenes de la moneda argiva de Antinoo. 


\author{
ROCÍO GORDILLO HERVÁS \\ LA REPRESENTACIÓN DE ANTINOO Y ADRIANO-ARES/MARTE \\ EN EL CONTEXTO ARGÓLICO
}

ABSTRACT: The aim of this article is to identify the masculine figure on the obverse of an Argolic coin dedicated to Antinous (RPC 3, 390) as the emperor Hadrian represented with the iconography of Ares/Mars. To this end, a comparison between another Argive coin dedicated to the emperor Hadrian and three statues of the god Mars (possibly) belonging to the Hadrianean period will be carried out. Additionally, the article will underline the importance of Hadrian's adventus for the city of Argos in relation to the choice of Ares/Mars for its numismatic iconography.

Keywords: Argos; Hadrian; Antinoeia; Ares; Mars; Temple of Venus and Roma; Hadrian's Villa.

El análisis iconográfico de la figura masculina en el anverso de una moneda acuñada en la ciudad de Argos y dedicada a Antinoo (fig. 1) $(R P C 3,390)$ ha dado como resultado distintas hipótesis sin que se haya alcanzado un consenso. El presente artículo analiza la moneda argiva en el contexto en el que fue acuñada, durante el periodo de gobierno del emperador Adriano, y ofrece una nueva interpretación para la identificación de la figura representada. En la primera parte del artículo se realiza un estudio detallado de la relación de Argos con Antinoo. Se explicita la importancia que adquiere la ciudad de Argos en relación con el culto al favorito del emperador de manera pública y privada que la hará ser una de las elegidas para albergar los agones Antinoeia. Seguidamente, se relaciona esta moneda con las distintas series monetales acuñadas por Argos durante el periodo adrianeo, en las que se publicitan las liberalidades y el acercamiento del emperador a la ciudad. En segundo lugar, se realiza un estudio iconográfico de algunas esculturas adrianeas y su posible relación con la figura de la moneda de Argos con motivo de plantear una nueva identificación de la misma: la figura posiblemente representa a Adriano según la iconografía de Ares/Marte. Finalmente, se presenta el posible adventus de Adriano a la ciudad de Argos como la razón de la elección de Ares/Marte para la moneda.

En otoño del 130 d. C. ${ }^{1}$ a la altura de la ciudad de Hermópolis el favorito de Adriano, el joven Antinoo, muere ahogado en el río Nilo mientras acompañaba al emperador y su corte en un viaje por Egipto ${ }^{2}$. Las causas

1. Hay varias versiones sobre la fecha exacta de la muerte de Antinoo. De forma general véase: GRENIER, 2008, p. 55.

2. Sobre Antinoo hay abundante bibliografía: Beaujeu, 1955, p. 242; Lambert, 1984; Meyer, 1991; Mambella, 1995; Birley, 1997, pp. 235-258; Mambella, 2000; Kuhlmann, 2002, pp. 136-139; Vout y Curtis, 2006; Galimberti, 2007, pp. 139-144; Mambella, 2008; Parlasca, 2009; JONES, 2010; THOMPSON, 2013. 
de la muerte aún siguen siendo un misterio. Algunas fuentes hablan de suicidio voluntario e incluso incitado por el consejo de los magi egipcios consultados por el emperador para averiguar cómo podía prolongar su $v$ vida $^{3}$. Tras el fallecimiento de Antinoo, Adriano instituye el culto al joven que se difunde rápidamente por las ciudades del imperio romano, quienes elevan estatuas representativas a su persona, construyen templos, celebran rituales y competiciones en su honor ${ }^{4}$.

Los agones dedicados a Antinoo, también llamados Antinoeia, están documentados principalmente a través de las fuentes epigráficas. Las inscripciones indican que se celebraron juegos efébicos en Atenas, Eleusis y Antinoopolis, y también grandes agones cívicos en Antinoopolis, BitinionHadriane, Tomis, Mantinea o Argos 5 . Entre el material para el estudio de estas competiciones destaca el estudio de G. Blum, quien en 1914 organizó un corpus numismático ordenado por ciudades en el que se recogen todas las monedas y medallones donde se representa a Antinoo. Según Blum, todas ellas se datarían en torno a los años 134-135 d. C. con motivo de la conmemoración de la primera penteteria de la defunción del favorito de Adriano $^{6}$. De entre las monedas destaca una pieza de bronce acuñada en Argos que Blum vincula directamente con los juegos Antinoeia de la ciudad. En el anverso de la misma se representa el perfil de Antinoo junto a la leyenda $\Theta E O N$ ANTINOON, lo que indicaría que se acuñó tras la muerte del joven. En el reverso se vislumbra una figura masculina de cuerpo entero y desnuda. La cabeza de la misma mira hacia la derecha, porta casco sobre su cabeza y presenta una tupida barba. La figura sostiene en su mano derecha una lanza y en el brazo izquierdo un escudo redondo ${ }^{7}$. Junto a ella, en el borde derecho se visualizan los restos de la leyenda АРГ $\mid \mathrm{EI} \omega \mathrm{N}^{8}$. Algunos de los investigadores que han realizado un estudio de esta pieza monetal han identificado la figura como un atleta participante

3. SHA, Hadr. 14.5-7; Dio, 69.11.2-3; Aur. Vict, Caes. 14.7-9. Sobre Adriano y la consulta de oráculos, magi y matemáticos véase: SHA, Hadr. 14.2.3; Amm. MARC, 22.12.8; BIRLEY, 1997, 244.

4. Paus, 8.9.7-8, 10.1; Euseb, Hist. Eccl. 4.8.2.

5. Para los juegos efébicos de Eleusis y Atenas véase: Graindor, 1922. Antinoopolis: Bernand, 1984, pp. 72-75, n. ${ }^{\circ}$ 5-8 y n. ${ }^{\circ} 10 ;$ id. 82-84, n. ${ }^{\circ} 9=$ SEG 28, 1458; ROBERT, 1952, BE 65, n. ${ }^{\circ}$ 180; P.OXY Hels, 25, lns. 17-18 = PAgON 4; FrISCH, 1986, pp. 76-77; PSI III, 199, lns. 4-11; P.LOND III, p. 165-166, n. 1164 i, lns. 9-12; P.OXY 705, lns. 48-51. Bitinion-Hadriane: IKlaudiu polis $65=I G R$ 73. Tomis: I.Tomis 52. Mantinea: Paus, 8.9.7-8, 10.1; Robert, 1980, p. 135, n. 16; STRASSER, 2003, pp. 258-260 = SEG 53, 1355; IG IV, 590, lns. 11-13.

6. Blum, 1914; Seltman, 1948, p. 80.

7. Descripción de Buum, 1914, p. 35, n. ${ }^{\circ}$ 1: "Homme barbu, nu, casqué, de face, la tète à g.; aux pieds de fortes chaussures montant au Mollet".

8. $R P C 3,390$. 
en alguno de los agones que se celebraban en Argos en el siglo II d. C. ${ }^{\text {. }}$ Sin embargo, la similitud de la representación de la figura de la moneda con algunas piezas escultóricas de época adrianea hace que sea necesario revisar esta interpretación.

El tipo iconográfico de la figura de la moneda argiva ha sido tradicionalmente relacionado con las competiciones agonísticas de la ciudad. Tanto G. Rathgeber como G. Blum indican que esta figura podría estar en conexión con el antiguo agon chalkeios (à $\gamma \dot{\omega} \nu \chi \alpha \dot{\lambda} \lambda \kappa \varepsilon เ \varsigma \varsigma)$, concurso relacionado con los rituales dedicados a la diosa Hera en Argos, donde al vencedor se le premiaba con un escudo ${ }^{10}$. Sin embargo, siguiendo a estos investigadores, el hecho de encontrar el semblante de Antinoo en el anverso indicaría que la moneda estaría relacionada con los agones cívicos que honraban a este personaje, es decir los Antinoeia ${ }^{11}$. Los juegos dedicados a Antinoo se encuentran documentados en una inscripción argiva del siglo II d. C., dedicada a Tito Estatilio Timócrates Memiano, heladarca y sumo sacerdote de los helenos (probablemente de la liga aquea), strategos de los aqueos, heladarca de los anfictiones, panhellene y finalmente agonoteta de varios festivales entre los que se encuentran los Antinoeia de Argos y de Mantinea ${ }^{12}$. Aunque esta sea la única mención de los juegos no creo que deba indicar, como propone S. Remijsen, que se hubieran celebrado una sola vez y probablemente con motivo de la conmemoración de las efemérides de Antinoo en su ciudad natal, sino que se celebraban periódicamente cada cuatro años ${ }^{13}$. La ausencia de documentación en los palmareses de los atletas no permite aclarar las disciplinas atléticas que constituían los juegos. Por otro lado, podría indicar que el prestigio de las fiestas no se había extendido más allá de la ciudad o que los juegos no habían obtenido la iselasis por lo que posiblemente resultaban poco atrayentes para los miembros de los sínodos de atletas y technitai.

La moneda en cuestión estaba conectada con el culto de Antinoo que se difundió tanto en los ambientes públicos como en los privados de la Argólide. En 1986 se halló una cabeza del joven en el santuario de Demeter Prosimna y Dioniso en Lerna. La pieza, de mayores dimensiones que el

9. Rathgeber, 1833, pp. 322-323; Blum, 1914, p. 35, n. ${ }^{\circ} 1$.

10. Pind, $N$. 10.22: «La contienda, de vero, por ganar el escudo de bronce, al pueblo convoca a la ofrenda del toro a Hera y al fallo de los Certámenes" (trad. Alfonso OrTega).

11. Rathgeber, 1833, pp. 322-323; Blum, 1914, p. 35, n. ${ }^{\circ}$ 1. La última hipótesis a esta iconografía ha sido aportada por PudiLl, 2014, 53, quien indica que la figura podría representar a Diomedes, héroe argivo, responsable del robo del Paladio, aunque también la relaciona con los juegos Antinoeia.

12. IG IV, 590, ln. 11-12 = CIG 1124; Oliver, 1970, p. 34; Fougéres, 1898, p. 517.

13. Remijsen, 2015, p. 60, n. 105. 
natural, porta una corona de hiedra sobre la cabeza y probablemente sostenía una antorcha y un thyrsus, lo que ha sido identificado con el carácter mistérico de las ceremonias que se realizaban en su honor ${ }^{14}$. En el caso de los ambientes privados, en Myloi se halló un complejo residencial con una estatua marmórea de Antinoo, así como el basamento de otra estatua probablemente de bronce, que presentaba una inscripción en la que Antinoo

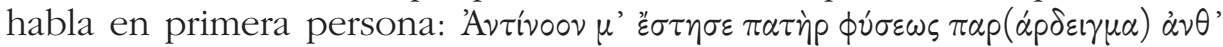
$\tilde{\eta} s \dot{\alpha} \theta \dot{\alpha} \nu \alpha \tau o \nu \mu \nu \eta \dot{\mu} \mu \nu \mu \eta^{\prime} \eta \eta \mu(\varepsilon) \dot{\alpha} \nu(\dot{\varepsilon} \theta \eta \kappa \varepsilon \nu)$. En el estudio de M. Galli, se asocia el término pater, que aparece en el epígrafe, con uno de los grados de iniciación en los rituales mistéricos, llegando a la conclusión de que en Myloi se reunía alguna asociación religiosa dedicada al culto de Antinoo ${ }^{15}$.

La ciudad argiva no solamente acuñó monedas para rendir homenaje al favorito de Adriano, sino que la efigie del emperador también aparece representada en varios anversos. Entre las monedas con la silueta del emperador hay una serie que se puede conectar con la pieza de Antinoo anteriormente comentada. En los ejemplos con Adriano, el anverso presenta la efigie del emperador junto a la leyenda KTICTHC, mientras que en el reverso se encuentra una figura masculina exactamente igual a la de la moneda de Antinoo exceptuando la ausencia de barba ${ }^{16}$. En el extenso estudio de Ch. Flament y P. Marchetti sobre la numismática argiva se indica que la figura masculina de la moneda adrianea podría representar al atleta ganador de los conocidos juegos Aspid de Argos, dedicados a Hera, ya que a los vencedores se les premiaba con un escudo redondo de bronce ${ }^{17}$. De

14. http://www.birmingham.ac.uk/schools/historycultures/departments/caha/ events/2017/seminar-stefanidou-tiveriou.aspx.

15. GaLLI, 2007, pp. 207-208. Sobre la inscripción: MeYER, 1991, pp. 125 y $210=$ SEG 41, 293.

16. $R P C 3,379$.

17. Flament y Marchetti, 2011, p. 57. En las fuentes epigráficas los juegos Aspid aparecen denominados como: $\dot{\eta} \dot{\xi} \xi$ "A

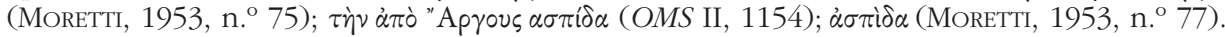
Sobre el escudo véase: PIND, O. 7. 152: "Cuatro veces ganó la muy famosa del Istmo, y de nuevo en Nemea y en la rocosa Atenas. Conocía el escudo de Argos y los trípodes forjados de Arcadia y Tebas". Sobre el escudo y los juegos: Apollod, Bibl. 2.2.1: "Linceo reinó sobre Argos tras Danao y engendró con Hipermnestra un hijo, Abas, y Abas tuvo con Aglaia, hija de Mantineo, dos hijos gemelos, Acrisio y Proeto. Estos dos ya rivalizaban estando todavía en la matriz, y cuando crecieron estuvieron en guerra por el reinado, y en el curso de la misma fueron los primeros en inventar los escudos". Véase también PLiN, HN 7.57.9; Hyg, Fab. 170, 273. Sobre el escudo y los juegos de Hera en Argos véase: PIND, O. 7. En los primeros juegos argivos dedicados a Hera ya se utilizaba el escudo como premio a los atletas. A este hecho se vincula la inscripción de la basa de la estatua de Nicoreon, rey de Salamina de Chipre, datada entre el 332-310 a. C. donde es honorado por los argivos por el envío de cobre para la fabricación de los premios del concurso de Hera: IG IV, 583; 
este modo, la iconografía de los reversos de la moneda de Antinoo y la de Adriano estaría claramente en conexión con el mundo agonístico. En el caso de Antinoo, siguiendo a Blum y recientemente Pudill, con los Antinoeia, pero en el caso de Adriano, la hipótesis de Ch. Flament y P. Marchetti plantea algunas preguntas: ¿por qué elige Argos asociar los juegos Aspid de Hera con el emperador?, ¿hay alguna asociación entre Adriano y los juegos?

Se podría sostener que la ciudad representa a los agones Aspid en la moneda de Adriano para publicitar alguna contribución del emperador a los agones como por ejemplo la inserción, renovación o rehabilitación de alguna prueba. A través de las fuentes documentales conocemos que hay una clara relación entre el emperador y el santuario de Hera en Argos, aunque no aparezca ninguna mención que lo asocie con los juegos dedicados a la diosa. Una inscripción argiva detalla la erección en el Heraion de una estatua del emperador (probablemente dedicada por la propia polis) en el 123 d. C., año en el que se conmemoraba su séptima tribunicia potestas $^{18}$. Por otro lado, en la descripción del templo de Hera que realiza Pausanias $^{19}$ se describe al emperador Adriano ofrendando un pavo real hecho con piedras brillantes porque "consideran a esta ave consagrada a Hera ${ }^{20}$. La ofrenda de Adriano al Heraion no pasó desapercibida en la ciudad y como tal fue representada en una serie monetal argiva. En el anverso de esta moneda aparece la efigie del emperador junto a la leyenda

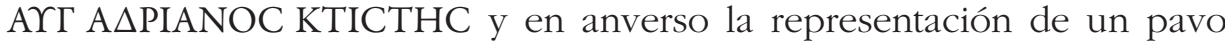
real acompañada de la leyenda AРГEI $\omega \mathrm{N}^{21}$.

AmandRY, 1983. La nomenclatura de los juegos de Hera en Argos cambia con el tiempo. En un primero momento los juegos se denominaban Hekatomboia, se realizaban en el santuario de Hera, próximo a Argos, y estaban destinados a la conmemoración de dicha divinidad. Sin embargo, durante el siglo v a. C., este término se abandona y se emplea desde entonces el de agones Hereos. Este hecho coincide con el traslado de los cultos a un nuevo recinto incluido dentro de la propia polis de Argos, donde se emplaza un templo a la diosa. De este modo, un ritual que estaba asociado a un santuario extraurbano se erige como uno de los cultos principales de Argos, esgrimiéndose en este momento como culto urbano de la polis. La última denominación datada en torno al siglo i d. C. coincide con la elevación a la caracterización de panhelénico del culto, titulándose ahora como $\dot{\eta} \dot{\xi} \xi$ ” Aprovs $\dot{\alpha} \sigma \pi i \varsigma$, esto es, agones Aspideos de Argos. Para un análisis del cambio de nomenclatura sufrido por los juegos en conexión con la epigrafía véase: AMANDRY, 1980, pp. 211-253.

18. CASKeY y AMANDRY, 1952, pp. 219-221: los editores de la inscripción proponen la integración del sustantivo $\theta$ còv en la segunda línea.

19. Paus, 2.17.1-7.

20. Paus, 2.17.6. Traducción de Herrero Ingelmo, 1994.

21. RPC 3, 377; Flament y MarchetTi, 2011, 58. 
La iconografía del pavo real de la moneda argiva está pensada para establecer una asociación inequívoca entre el emperador Adriano y el Heraion de Argos. De este modo, si como indican los investigadores las figuras de la moneda de Adriano y de la de Antinoo con el escudo y la lanza (RPC 3, 379 y 390) están haciendo referencia a un juego, estas tendrían que ser un símbolo inequívoco de la festividad particular argiva. La única relación que se puede realizar de la iconografía del personaje armado con el mundo agonístico es la carrera hoplítica, donde el atleta (boplitodromos) debía correr ataviado con el armamento propio de un hoplita. En el caso de los juegos Aspid no se ha conservado ningún documento en el que se mencione esta prueba ${ }^{22}$. Pero los juegos Aspid no son los únicos juegos que organiza la ciudad de Argos. Desde el siglo v a. C., Argos es responsable de la celebración de uno de los juegos del archaia periodos, los Nemeos ${ }^{23}$.

22. En los palmareses de los atletas las pruebas que se relacionan con los agones de Hera son: Dolichos (atleta T. F. Metrobio: MoretTi, 1953, n. ${ }^{\circ}$ 66; Gouw, 2009, n. ${ }^{\circ}$ 158. Atleta M. Aurelio Abas: MoretTI, 1953, n. ${ }^{\circ}$ 76. Atleta M. Aurelio Demostrato Damas: MoretTI, 1953, n. ${ }^{\circ}$ 84); Pancracio (atleta T. F. Artemidoro: $I G$ XIV, 746; MoretTI, 1953, n. ${ }^{\circ}$ 67; Gouw, 2009, n. ${ }^{\circ}$ 155. Atleta M. Aurelio Asclepiade, Moretri, 1953, n. ${ }^{\circ}$ 79); Pale (Atleta, T. F. Archibios: IG XIV, 747; MoretTi, 1953 n. $^{\circ}$ 68; Gouw, 2009 n. $^{\circ}$ 153); Pygme (atleta Marciano Rufo: SEG 13, 540; Moretti, 1953, n. ${ }^{\circ}$ 69; Gouw, 2009, n. ${ }^{\circ}$ 102. Atleta Focion: I. Eph. 1605; MoretTi, 1953 n. $^{\circ}$ 73; Gouw, 2009, n. ${ }^{\circ}$ 115. Atleta M. Aurelio Demostrato Damas: MoretTi, 1953, n. ${ }^{\circ}$ 84); Pentatlon (Atleta desconocido: I. Eph. 2072; MoretTi, 1953, n. ${ }^{\circ}$ 75; Gouw, 2009, n. ${ }^{\circ}$ 2); Carrera sin especificar (Atleta M. Aurelio Hermagoras: IG XIV, 739; MoretTI, 1953, n. ${ }^{\circ}$ 77; Gouw, 2009, n. ${ }^{\circ}$ 92); Aules (Participante desconocido, MoretTi, 1953, n. ${ }^{\circ}$ 81); Heraldos (Participante Valerio Eleto, MoretTi, 1953, n. ${ }^{\circ}$ 90).

23. La historia de los juegos Nemeos es singular, ya que su organización estuvo administrada por dos poleis, la de Cleonas y Argos. Las fuentes indican que las competiciones estuvieron controladas hasta los años 415-410 a. C. por Cleonas, ciudad que se encuentra a cinco kilómetros al este del santuario de Zeus Nemeo (PInd, Nem. 10. 42; 4.17; PluT, Arat. 28; Miller, 1977, pp. 9-10) A partir de dicha fecha, el recinto sacro se destruye por lo que la celebración de los juegos se traslada a la polis de Argos, quien empieza a ser la responsable de su organización (Xenon, Hell. 4.7.2-3; Mari, 2008). Con la llegada de Macedonia al territorio griego (MARI, 2002, pp. 190-197) el santuario se restaura y los juegos vuelven a su localización tradicional en el 335 a. C. aunque siempre bajo el control de la polis argiva. Los juegos se celebraban desde el 270 a. C. en la ciudad argiva (AMANDRY, 1980, pp. 248-249). Sin embargo, hay un texto datado en el 235 a. C. que contradice a los demás, asî que relata la utilización del santuario para la realización de unos juegos Nemeos dirigidos por Arato, que constatan una excepción: PluT, Arat. 28. 3-4: S.G. Miller sugiere una fecha específica de la llegada de los juegos a Argos definitivamente en el 271 a. C., véase: MiLler, 2001, p. 93. En contra: BRADEEN, 1966, p. 29, quien utiliza la inscripción sobre la locución que L. Mummio realiza en el teatro de Nemea en el 145 a. C. y un pasaje de Estrabón: MagnetTo, 1997, n. ${ }^{\circ}$ 41. Las excavaciones llevadas a cabo en el santuario de Nemea indican que el sitio permanece abandonado desde mediados del siglo III a. C.: Miller, 1990; Miller et alii, 2001, 115; KNAPP y Mac IsAac, 2005, p. 8. 
Pausanias describe cómo Adriano reforma los agones del santuario de Zeus Nemeo:

Arístides de Elis obtuvo una victoria en Olimpia en la carrera de armados, en la doble carrera en Pito, y en Nemea en la carrera de caballos infantil, según muestra la inscripción que hay sobre él. La longitud de la carrera de caballos es de dos carreras dobles, y habiendo sido excluida de los Juegos Nemeos e Ístmicos el emperador Adriano la restauró para los argivos en los Juegos Nemeos de invierno ${ }^{24}$.

En este pasaje se observan las dos reformas llevadas a cabo por el emperador. En primer lugar, cambia el calendario agonístico de la ciudad y establece que los concursos pasen a celebrarse en invierno en vez de verano, como hasta entonces se venían haciendo. Este hecho se justifica a través de la epigrafía. En una estela hallada en la ciudad de Alejandría en la Tróade se hallaron inscritas tres cartas del emperador Adriano al $\sigma v v o ́ \delta \omega$

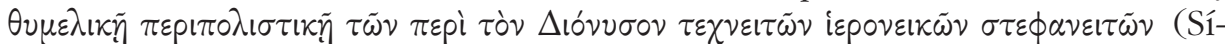
nodo Timélico e Itinerante de los vencedores sagrados y coronados artistas de Dioniso). En la segunda de ellas, fechada en el 134 d. C., el emperador reorganiza el calendario agonístico del imperio. El nuevo calendario se estructura en torno a un ciclo de cuatro años que se inicia con la celebración de los juegos Olímpicos de Pisa y finaliza con los Panhelenos de Atenas. El emperador inserta los juegos Nemeos, que hasta entonces habían sido celebrados en verano ${ }^{25}$, en torno a los meses de noviembre y diciembre del segundo año olímpico. En segundo lugar, Adriano restaura una disciplina ecuestre tradicional de los juegos que, por razones desconocidas, había sido eliminada de la competición.

De forma general hay muy poca documentación sobre los nuevos juegos Nemeos de invierno. Es probable que siguieran con las pruebas y la misma organización de los Nemeos tradicionales que, en este caso, contaban con carreras hoplíticas:

Los argivos hacen sacrificios a Zeus también en Nemea, y eligen un sacerdote de Zeus Nemeo, e incluso organizan un concurso de carreras para hombres armados en los Juegos Nemeos de invierno ${ }^{26}$.

Pausanias indica que una de las disciplinas de los juegos Nemeos eran las carreras hoplíticas, por lo que las figuras masculinas de los reversos de la moneda de Adriano y la de Antinoo podría hacer referencia a estos

24. Paus, 6.16.4. Traducción Herrero Ingelmo, 1994.

25. Calendario de Adriano: Petzl y Schwertheim, 2006; Jones, 2007; Strasser, 2010; Le GuEN, 2010, p. 213; GORDILLO, 2017.

26. Paus, 2.15.3. Traducción de Herrero Ingelmo, 1994. 
juegos. Sin embargo, en otra serie monetaria la ciudad de Argos difunde el papel del emperador Adriano como renovador de los juegos Nemeos. Para ello la polis elige una iconografía estándar, o sea la corona de perejil con la que se premiaba a los vencedores en los juegos Nemeos. En esta serie, el emperador vuelve a aparecer en el anverso con la misma leyenda de las otras monedas ( reverso se representa dicha corona con la leyenda APГEI $\omega \mathrm{N}$ en su exterior y NEMEIA en su interior ${ }^{27}$. De este modo, parece difícil poder justificar la elección iconográfica del personaje armado en la moneda de Adriano y la de Antinoo como símbolo de la restauración de los juegos llevada a cabo por el emperador. La figura hoplítica en sí misma no sería un símbolo claro de la intervención imperial en los agones Nemeos, ya que el emperador no introduce la carrera hoplítica. La única contribución del emperador en los agones argivos fue en la rehabilitación de una prueba ecuestre en los juegos de Nemeos que podría quedar representada a través de la corona anteriormente citada.

La escasa documentación epigráfica relativa a los Antinoeia argivos hace imposible conocer las disciplinas que compondrían dicha competición. Sin embargo, en la vecina polis de Mantinea se organizaban juegos en honor de Antinoo de donde podemos extraer información sobre cómo podrían haber sido los Antinoeia de Argos. La documentación indica que los Antinoeia de Mantinea incluían el pancracio, disciplina estrella de todos los juegos atléticos. En los palmareses de M. Aurelio Demostrato Damas $^{28}$ y de M. Aurelio Asclepiades ${ }^{29}$, famosos pancratistas, se indica que ganaron dicha prueba en Mantinea. Los mismos juegos podrían aparecer mencionados en los palmareses de un pentatleta desconocido de Éfeso

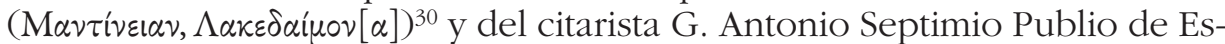
mirna ( $\Lambda \alpha \kappa \varepsilon \delta \alpha i \mu o v \alpha, M \alpha v \tau i v \varepsilon i \alpha \nu)^{31}$. De esta manera, no hay mención ninguna a las pruebas de carrera hoplítica y por lo tanto no se puede establecer su presencia o ausencia en las competiciones.

Sin embargo, la identificación de esta figura con un hoplitodromos merece ser revisada. Los corredores de la carrera hoplítica solían llevar

27. RPC 3, 368 y 381; Flament y Marchetti, 2011 p. 56.

28. I. SARDIS 79.B = IGR IV, $1519=$ IAG 84; ROBERT, OMS II, 1022-1023; MORETTI, 1953, n. ${ }^{\circ}$ 84; STRASSER, 2003, 258-260 = SEG 53, 1355.

29. M. Aurelio Asclepiades: $I G$ XIV, $1102=I G U R$ I, $240=$ MoretTI, 1953 , n. ${ }^{\circ} 79$.

30. MoretTI, 1953, n. ${ }^{\circ} 75, \ln .15$.

31. G. Antonio Septimio Publio: I. Smyrna $659=$ CIG $3209=I G R R$ IV, 1432. Sobre la asociación de estos juegos con los Antinoeia: FougÉres, 1898, p. 517. L. Robert proponía la identificación de los juegos mantineos de estas dos últimas inscripciones con los agones del koinon de arcadios (ROBERT, 1980, p. 135, n. 16). 
grebas, yelmo y escudo de bronce ${ }^{32}$. Ni en las distintas representaciones iconográficas ni en las fuentes literarias se mencionan la lanza, arma que por otro lado aparece en el personaje masculino de la moneda de Antinoo. El hecho de que el hoplitodromos no portara la lanza era para evitar llevar un estorbo para el atleta y sus rivales, así como evitar el peligro que supondría en caso de caída. De este modo, considero que la lanza de la figura es el elemento fundamental para indicar que el personaje no debe identificarse como un boplitodromos sino como un guerrero.

En el trabajo sobre Antinoo llevado a cabo por L. Dietrichson en el siglo XIX la iconografía del reverso de la moneda dedicada al joven es identificada con el dios Ares, aunque sin argumentación ${ }^{33}$. Igualmente, en el estudio numismático llevado a cabo F. Imhoof-Blumer y Percy Gardner la iconografía del reverso de la moneda de Adriano es identificada con Ares. Pero en este caso ¿cuál sería la relación existente entre Argos, Ares y Adriano, así como Argos, Ares y Antinoo para que la ciudad haya considerado su elección?

La figura de Ares junto a la del emperador Adriano se encuentra también en la iconografía monetal del reverso de monedas de otras ciudades orientales. En una serie de Alejandría Ares queda representado con la panoplia militar, casco, armadura, sosteniendo una lanza en una mano y el parazonium en la otra. En una serie de Sagalassos Ares lleva la misma vestimenta militar, pero deja sus armas para sostener una representación de la victoria en su mano derecha y un cetro en la izquierda. En una serie de Filipopolis el dios igualmente vestido lleva en su mano derecha una patera y en la izquierda una lanza que apoya en el suelo junto a un escudo redondo ${ }^{34}$. Como se puede apreciar en todas estas acuñaciones la representación del dios es más o menos similar. En todas ellas aparece con la misma vestimenta militar, aunque sostiene distintos objetos en sus manos. Sin embargo, las dos monedas argivas de Antinoo y de Adriano son las únicas representaciones de Ares/Marte desnudo portando la lanza y el escudo. En el resto de emisiones cívicas del periodo adrianeo el dios

32. Paus. 2.11.8; id. 6.10.4; PIND. P. 9.1; id. I. 1.23. De forma general véase: Golden, 2004, pp. 84-85.

33. Dietrichson, 1884 , p. 294; ImHoof y Gardner, 1964, p. 42, n. ${ }^{\circ} 29$. Esta interpretación es seguida en el $R P C$ 3, 390: http://rpc.ashmus.ox.ac.uk/coins/3/390/.

34. RPC 3, 390-392; Mionnet Supp. 4.40. Alejandría: $R P C$ 3, 5096, 5344, 5479, 5480, 5525, 5526, 5527, 604, 5952, 5953, 5954. Filipopolis: RPC 3, 750 y Sagalassos: $R P C$ 3, 2803. Sobre la relación de Adriano y Marte en algunas piezas monetales véase: Vermeule, 1955. 


\section{ROCÍO GORDILLO HERVÁS \\ LA REPRESENTACIÓN DE ANTINOO Y ADRIANO-ARES/MARTE \\ EN EL CONTEXTO ARGÓLICO}

está vestido bien con coraza militar y $\operatorname{casco}^{35}$ o con una túnica ${ }^{36}$ mientras sostiene una lanza o en ocasiones un parazonium. El hecho de que la figura desnuda con lanza, escudo y casco aparezca solamente en monedas argivas que llevan el emperador Adriano en el anverso podría indicar que existía alguna vinculación especial entre la ciudad y el emperador cuyo nexo de unión era, posiblemente, la divinidad Ares/Marte.

La semejanza de la iconografía de las monedas argivas de Antinoo y Adriano con algunas representaciones escultóricas del dios Ares/Marte de la misma época nos permite hipotetizar que las figuras masculinas de las piezas numismáticas estén realmente identificando a esta divinidad. En el recinto del Canopo de la villa del emperador en Tívoli se encontró, durante las excavaciones de 1954, una escultura tradicionalmente identificada con el dios Marte. La estatua, de tamaño mayor que el natural, podría haber sido una copia con leves modificaciones de un original griego de mitad del siglo v a. C. Esculpida en mármol pentélico, está datada en los años finales del gobierno adrianeo. La estatua representa a un joven desnudo, imberbe y de proporciones atléticas que viste un casco corintio rematado con una cresta. Con su mano izquierda sostiene un escudo redondo que se apoya sobre un tronco de árbol, mientras que la derecha debería portar un elemento que no se conserva ${ }^{37}$. La teoría tradicional hipotetiza que la figura representa al dios Ares/Marte, ya que este normalmente se representaba con atributos militares tales como un casco de guerra y un escudo. Sin embargo, F. Berger identifica la estatua con el héroe ateniense Teseo e indica que sigue el modelo escultórico del Teseo que los atenienses pusieron como decoración en su tesoro de Delfos con motivo de la celebración de la batalla de Maratón ${ }^{38}$. Esta hipótesis es seguida por E. R. Knauer, para quien la estatua délfica habría sido levantada de manera que los visitantes al santuario oracular identificaran a Cimón, héroe ateniense de las guerras médicas, nada más verla ${ }^{39}$. Otra hipótesis sugiere que la estatua estaría representando a un boplitodromo, como indica E. Minakaran-Hiesgen tras un estudio exhaustivo de la escultura. Su suposición está basada en el objeto que la escultura podría portar en su mano derecha, que podría llevar un ramo de flores, símbolo de la victoria atlética. De este modo, sostiene

35. En otro tipo monetal se representa tan sólo el busto del dios Ares con un casco sobre su cabeza: $R P C 3,5072,5568$. Véase también la representación de Marte en las monedas adrianeas BMCCRE 255, n. ${ }^{\circ} 109$ y $115 ; i d .325$, n. ${ }^{\circ} 674-675$. Marte toracato en las monedas de Trajano: BMCCRE 55, n. ${ }^{\circ} 158-160 ; i d$. 153 , n. ${ }^{\circ} 737-739$ y 154, n. ${ }^{\circ} 742 \mathrm{~A}$.

36. $R P C 3,5096,5344,5527$.

37. Museo de Villa Adriana n. ${ }^{\circ} 2262$.

38. BERGER, 1958.

39. Knauer, 1992. Pensabene, 2011, pp. 21-22. Paus, 10.10.1-2; Plut, 5.2-3. 
que podría ser una copia de la estatua de bronce del atleta Epicarino realizada por Critias y que se hallaba en la acrópolis ateniense ${ }^{40}$. Siguiendo con la misma idea, C. O. Pavese compara la estatua con los dos bronces de Riace, indicando que todas ellas son hoplitodromos. Según este investigador la estatua representa a un efebo debido a que se representa imberbe y con pelo rizado en el pubis, y a través de la comparación del estilo del cabello con el tipo ático concluye que la figura debería ser una copia de un original que se asociara a un efebo que habría ganado la carrera hoplítica durante la celebración de las panateneas.

La hipótesis que identifica la escultura con el dios Ares/Marte es la más aceptada. Siguiendo este camino, J. Raeder reutiliza la idea de MinakaranHiesgen para quien la estatua sostendría en su mano derecha un ramo. Por otra parte, indica que el escudo redondo que sostiene en su mano izquierda no es más que la representación de un escudo romano, o sea un clipeus, y que debido a sus pequeñas proporciones no podía ser del tipo usado en batalla. Por ello, propone la identificación del escudo como un clipeus virtutis, símbolo de gloria, victoria y paz. De esta manera, J. Raeder identifica la estatua con un Marte Pacificador (Mars pacifer) y lo justifica con el hecho de que la escultura está completamente desnuda tal y como Marte aparece en otras iconografías monetarias romanas ${ }^{41}$.

En el reverso de la moneda dedicada al emperador Adriano en Argos la figura masculina comparte las mismas características de la escultura de Marte de Villa Adriana: desnudo, sin barba, con casco y con escudo redondo. Es probable por lo tanto que la figura masculina de la moneda con Adriano en el anverso identifique a Marte de la misma manera en que aparece en Villa Adriana, aunque con lanza. De este modo, la moneda argiva propagaría la idea de las dos fundaciones de Roma: 1) una mítica asociada con Marte, divinidad ancestral de la ciudad y del imperio y, 2) la nueva del siglo II d. C., asociada con Adriano, nuevo padre y fundador no solo de la ciudad de Roma sino también como nuevo KTICTHC de Argos, tal y como se indica en la leyenda numismática.

$\mathrm{Si}$ en la moneda argiva con el anverso del emperador Adriano se puede identificar la figura del reverso con Ares/Marte, en la moneda de Antinoo también la figura del reverso debería representar la misma divinidad. Sin embargo, todavía se tendría que justificar la existencia de una relación entre la iconografía de Ares/Marte y la efigie de Antinoo. Ni en las fuentes literarias, ni en la epigrafía ni en el registro iconográfico de

40. Paus, 1.23.9. Minakaran-Hiesgen, 1980; Pavese, 1988.

41. Ares/Marte Pacificador: Raeder, 1983, p. 309; Aurigemma, 1996, p. 124, fig. 123; Moesch, 2000, pp. 220-222, n. 34 con bibliografía; Pensabene, 2009, p. 387. 
Antinoo aparece ninguna asociación explícita por lo que la pregunta es: ¿por qué ha elegido Argos representar a Ares en las monedas del favorito del emperador? La hipótesis que aquí presento es que esta moneda lleve en el reverso a Adriano siendo representado como Ares/Marte, y no al dios per se. Como se ha comentado anteriormente, la figura del reverso de esta moneda presenta una distinción fundamental con la figura de la moneda con Adriano, la barba. En la moneda dedicada a Adriano el dios no lleva barba mientras que en la de Antinoo sí. De hecho, la representación de la barba de esta pieza monetal parece ser un poco exagerada, como si el grabador hubiera querido enfatizar este elemento para diferenciar entre la representación imberbe de la divinidad y Adriano como Ares/Marte.

La asociación de Adriano con Ares/Marte aparece en dos estatuas adrianeas que han sido talladas siguiendo modelos escultóricos clásicos griegos. La primera pieza a tratar es la estatua conservada en los Musei Capitolini de Roma que toma como modelo el conocido Ares Borghese atribuido a Alcámenes, escultor griego del siglo v a. C. ${ }^{42}$. La estatua ha sido clasificada por C. Evers con el tipo Chiaramonti 392 que se desarrolla durante los primeros años del gobierno del emperador Adriano (118-121 d. C.). Presenta un tamaño mayor que el natural, y el emperador aparece desnudo y con la musculatura marcada. Sobre los pectorales y la zona abdominal lleva una cinta, distintiva de su imperium y sobre la cabeza un casco rematado con una pequeña cresta. En el brazo izquierdo sostiene un escudo redondo y en la mano derecha parece portar un elemento que no se conserva. Debido a la asociación de la divinidad con el emperador en el rostro se aprecia la característica barba de Adriano, atributo que lo distingue del propio dios ${ }^{43}$.

Existe otra pieza, aunque más controvertida, que podría representar a Adriano como Marte, el conjunto estatuario, hallado cerca de St. Maggiore en Roma y conservado en el Museo del Louvre, donde se representa a la pareja Venus y Marte ${ }^{44}$. Esta pieza es una copia de un grupo escultórico de la pareja Afrodita y Ares, probablemente del siglo v a. C. De proporciones iguales a las naturales, presenta a Venus dirigiendo sus brazos hacia Marte quien aparece representado con barba y un casco en la cabeza, un balteus sobre el torso y un parazonium en su mano derecha. Junto a la pierna

42. Museo del Louvre, número de inventario MR 65 (Ma 866). Sobre el Ares Borghese y la escultura de Adriano véase: HARTSWICK, 1990, p. 280, n. ${ }^{\circ} 22$.

43. Museos Capitolinos, número de inventario MC 0634. Wegner, 1956, pp. 31, 67, 107; Evers, 1994, pp. 159-160, n. ${ }^{\circ} 100$. Avagliano, 2011, indica que la estatua estaría representando a un efebo, seguramente al héroe Teseo.

44. Museo del Louvre, número de inventario MR 316 (MA 1009). 
izquierda del dios se encuentra un tronco sobre el que reposa una armadura $^{45}$. La hipótesis tradicional ha identificado este tipo con la celebración de la concordia, es decir la armonía matrimonial, en las parejas imperiales de época antonina ${ }^{46}$. Siguiendo esta hipótesis, la pareja de dioses representaría, de manera más o menos fidedigna, al emperador y a su compañera. En el caso que nos ocupa, el grupo escultórico del Museo del Louvre tradicionalmente se identifica con la pareja Adriano-Sabina ${ }^{47}$. La asociación Adriano-Marte podría haber representado un elemento fundamental para la nueva política protagonizada por el emperador Adriano. Según la tradición mitológica Rómulo y Remo eran descendientes directos de Venus, madre del héroe Eneas, quien tras su huída de la Troya logra, tras muchas vicisitudes, recalar en Italia acompañado de su hijo Ascanio. Este último será el responsable de la fundación de la ciudad de Alba Longa cuyo gobierno va a estar al cuidado de sus herederos. Uno de ellos, el rey Amulio, hizo que su única hija, Rea Silvia, fuera una vestal para que no tuviera descendencia porque tenía miedo de que pudieran usurparle el poder. Sin embargo, el dios Marte sedujo a la joven, de cuya unión nacieron Rómulo y Remo, fundadores y primeros reyes de la ciudad de Roma. De esta manera, Adriano junto a su compañera Sabina quedarían representados a través de su asociación con Venus y Marte como los nuevos padres de Roma. El emperador Adriano preside las celebraciones del Natalis Urbis del $121 \mathrm{~d}$. C. en conexión con la consagración del nuevo templo dedicado a Venus y Roma, un templo que además parece tomar como modelo planimétrico el templo de Afrodita y Marte de la ciudad griega de Argos.

45. Durante el siglo II d. C. esta tipología iconográfica también se encuentra en el reverso de algunas monedas (BMC 4, 543-44).

46. De Kersauson, 1996, p. 146.

47. Id. 147. Esta hipótesis ha recibido muchas críticas. En primer lugar, un análisis detallado de los retratos del grupo escultórico indica que fue alterado en época posterior. De hecho, la cara femenina no se puede relacionar con los retratos de Sabina conocidos. Los investigadores proponen su identificación con Faustina la Menor, por lo que pudo haber habido una sustitución de la cabeza de la diosa. Por otro lado, en el trabajo de D. E. E. Kleiner se analizan todas las esculturas representativas de este tipo iconográfico para concluir que todas ellas serían retratos de "wealthy members of Roman society who emulated the conceit of mythological portraiture popular among the members of the Imperial circle, (KLEINER, 1981, p. 539). Recientemente, esta hipótesis ha sido seguida por R. Kousser quien propone dos contextos para el florecimiento de este tipo de representaciones aristocráticas: 1) para ser objeto de decoración dentro de las villas y casas urbanas; 2) vinculadas a la representación de los fallecidos en espacios fúnebres (Kousser, 2007). Otras críticas a esta hipótesis provienen de Wegner, 1956, pp. 45-49, para quien la cabeza de Marte no se puede relacionar con ninguno de los tipos estilísticos propios del emperador Adriano y la cabeza de Venus sería un retrato de Faustina la Menor. 
En la periégesis de Pausanias se encuentra una descripción del templo argivo:

El camino que lleva a Mantinea desde Argos no es el mismo que el que conduce a Tegea, sino que parte de las puertas que están junto a la Dírade. En este camino hay un santuario doble, que tiene una entrada por el oeste y otra por el este. En la última hay una xóana de Afrodita, y en la de occidente una de Ares. Dicen que las imágenes son ofrendas de Polinices y de todos los argivos que fueron con él en la expedición para vengarse ${ }^{48}$.

El templo, que era usado por los argivos para hacer balance de sus campañas militares antes de entrar en la ciudad ${ }^{49}$, presentaba una planimetría singular. Pausanias menciona un santuario doble con dos entradas diferenciadas, una orientada al este y otra al oeste. Según los estudios de U. Fusco el naos del templo estaría dividida por un muro central en dos salas yuxtapuestas de idénticas dimensiones. De este modo, el espacio sacro quedaría compartimentado en dos mitades independientes a las que se accederían por dos accesos diferentes, orientados a este y oeste ${ }^{50}$. Como indica U. Fusco, el uso de este tipo de planta es bastante inusual en los santuarios dobles, ya que normalmente estos recintos suelen presentar dos naos paralelos a los que se accede por dos puertas distintas orientadas hacia el mismo punto cardinal. Entre los pocos templos que siguen el mismo modelo del santuario argivo se encuentra el templo de Venus y Roma, que fue construido ex novo por el emperador Adriano junto a la Vía Sacra de la capital romana. El edificio se levanta sobre una plataforma elevada, de 145 x 100 metros, a la que se accede a través de siete escalones. Es un templo anfipróstilo cuyo naos está rodeado por tres filas de diez columnas en sus lados menores (este-oeste) y dos filas de veintidós columnas en sus lados mayores (norte y sur). La originalidad de este templo reside en que el naos, exactamente como el del templo argivo, está dividido por un muro en dos salas yuxtapuestas de idénticas dimensiones, quedando el espacio sacro compartimentado en dos cellae independientes con acceso propio orientadas, de nuevo, una al este y otra al oeste. Las cellae están a su vez seccionadas en tres naves por dos filas de seis columnas que ordenan el espacio $^{51}$.

48. Paus, 2.25.1. Traducción de Herrero Ingelmo, 1994. Sobre la relación entre el culto de Afrodita y Ares véase: PIRONTI, 2005.

49. Tomlinson, 1972, p. 208.

50. Fusco, 2016, fig. 9.

51. Sobre el templo de Venus y Roma véase: Barattolo, 1978; Boatwright, 1987, pp. 121-141; Cassaella y Panella, 1990; Calandra, 1996, pp. 72-76; STamper, 2005, pp. 206-212; 
La similitud planimétrica de los naoi de los templos de Argos y Roma han sido la base de U. Fusco para considerar la posibilidad de que Adriano pudiera haber tomado como modelo el templo argivo para su nuevo templo de Venus y Roma. Ahora bien, si el emperador utilizó este templo debió de haberlo conocido o al menos visitado durante uno de sus viajes por Acaya. El templo de Afrodita y Ares es anterior al 418 a. C., año en el que Tucídides fecha la búsqueda de asilo del general argivo Trasilo a un altar cercano al río Caradro junto al que se localiza el templo ${ }^{52}$. Es posible que el emperador Adriano lo visitase durante su viaje 124-125 d. C. a Grecia en el que se desplaza desde Argos a Mantinea ${ }^{53}$. A la salida de Argos, el cortejo imperial tomaría la vía principal que unía ambas ciudades y que pasaba por el templo de Afrodita y Ares. Como indica U. Fusco, no sería extraño pensar que el emperador pudiera haber visitado el templo argivo y que su planimetría hubiera servido de ejemplo para edificar el templo de Venus y Roma ${ }^{54}$. Uno de los argumentos a favor de esta hipótesis es que el templo romano se construye con posterioridad a la visita del Emperador a Argos. La consagración del lugar que albergaría el templo romano se fecha en coincidencia con las celebraciones del aniversario del nacimiento de Roma en el 21 de abril del año 121 d. C. (Natalis Urbis), para lo que el Emperador transformó, de forma puntual, la fiesta tradicional romana que se celebraba en ese día, Parilia, en los ludi circenses Romaía ( $\mathrm{P} \omega \mu \alpha i \alpha)^{55}$. Sin embargo, el edificio no se empezó a construir hasta el 125 o 126 d. C., fue inaugurado en el 135 d. C. sin finalizar, y se culminó con Antonino Pío en torno a los años 140-145 d. C. ${ }^{56}$. Un argumento a favor de que Adriano hubiera modelado su templo según el de Argos es aportado por E. Calandra, quien señala que el arquitecto del templo romano es el propio Adriano, quizás motivado por la muerte de Apolodoro, arquitecto de renombre encargado entre otras construcciones de las termas romanas de Trajano ${ }^{57}$. Si se acepta esta hipótesis, Adriano pudo haber utilizado el templo argivo para enfatizar su asociación con Ares/Marte en su papel simbólico como

Fabiani y Fraioli, 2010.

52. Thuc, 5.60.6.

53. Viajes de Adriano, Weber, 1907, p. 184; Birley, 1997, p. 179; id. 2004, pp. 68-69; HøJTE, 2000; Opper, 2008, 20, fig. 4; Lo Monaco, 2014, 29.

54. FusCo, 2016, p. 114.

55. Атн, Deipn. 8.361. De forma general véase: TuRCAN, 1964. Acuñaciones monetarias que celebran el acto: BMCCRE n. ${ }^{\circ}$ 700-703, 750-756.

56. Boatwright, 1987, pp. 121-124; Stamper, 2005, pp. 207-209; CARANDini y PaPI, 2019, pp. $180-182$.

57. Sobre la historia de Apolodoro y Adriano véase: Dio, 69.4.4; Calandra, 1996, p. 75; BOATWRIGHT, 1987, pp. 119-121. 
padre de Roma. De esta manera, la identificación iconográfica de Adriano con Ares/Marte estaría conectada con las celebraciones del natalicio de la ciudad y la consagración del templo de Venus y Roma. Si se acepta esta hipótesis, resultaría evidente la importancia de la elección argiva de Marte como iconografía en las monedas adrianeas. El emperador, al haber elegido el templo de Afrodita y Ares como modelo arquitectónico, se asocia a Argos través de la divinidad masculina del templo argivo, Ares. Esto explicaría como en la moneda de Argos dedicada al emperador aparezca en el anverso Adriano y en el reverso el dios Ares/Marte, mientras que en la moneda con el anverso de Antinoo aparezca Adriano como Ares/Marte.

\section{CONCLUSiÓN}

La fundación del culto de Antinoo por el emperador Adriano en el siglo II d. C. hizo que las ciudades contaran con un nuevo método de acercamiento al poder imperial. Esto se manifiesta a través de la erección de estatuas y templos, así como la celebración de rituales dedicados al joven que incrementan el prestigio no solo de la ciudad sino de las élites que se encargan de su organización. En el caso de Argos la epigrafía menciona los Antinoeia, juegos atléticos y musicales dedicados a Antinoo. Varios autores han intentado establecer una conexión entre estos concursos y la figura masculina barbada y armada con lanza, escudo y casco que aparece en el reverso de una moneda acuñada en Argos, identificándola como un hoplitodromos. Pero esta interpretación está socavada por la presencia de la lanza, que no formaba parte de la panoplia de los hoplitodromoi. Además, la figura masculina con lanza no es única, ya que en otra moneda de la misma ciudad, cuyo anverso presenta al emperador Adriano, aparece la misma figura aunque sin barba, por lo que su conexión con los Antinoeia hay que ponerla en duda.

Es muy posible que la figura del reverso de las dos monedas (la de Antinoo y la de Adriano) sea el dios Ares/Marte, pero en el caso de la moneda de Antinoo más específicamente a Adriano representado como Ares/Marte. La relación entre la ciudad de Argos y Adriano como Ares/ Marte podría derivar de la similitud arquitectónica del templo de Afrodita y Ares de Argos y el templo de Venus y Roma de la capital imperial. El interés personal del emperador en la construcción del templo en Roma es la base para que U. Fusco considere que Adriano pudo haber visitado el santuario argivo y trasladado su planta de doble cella en el templo de Roma. La similitud de la iconografía de la moneda de Adriano con la estatua del Ares localizada en el Canopo de Villa Adriana induce a pensar 
que en la moneda de Adriano se representa al dios per se, mientras que en el anverso aparece el propio emperador. Por otro lado, en la moneda de Antinoo, la figura masculina lleva barba, lo que indicaría que se trata de la representación de Adriano-Ares/Marte como se encuentra en las estatuas de los Musei Capitolini de Roma y posiblemente en la del Museo del Louvre. La asociación Adriano-Ares/Marte se data de principios del reinado de Adriano, mientras que la moneda de Antinoo es posterior a su muerte en el 130 d. C. Es probable que el tipo iconográfico Adriano-Ares/Marte fuera establecido antes del proceso de acuñación de la moneda argiva y que, por tanto, sería conocido por la ciudad de Argos. En conclusión, considero que Argos utiliza la moneda de Antinoo para mandar dos mensajes claros tanto al emperador como a las otras ciudades griegas: 1) la lealtad y devoción de Argos hacia el emperador y a su nueva política religiosa en la que el culto Antinoo goza de un papel principal; 2) el papel jugado por Argos en la elección por parte de Adriano del modelo arquitectónico el templo de Venus y Roma.

\section{ABREVIATURAS}

BMCCRE: H. Mattingly, A Catalogue of The Roman Coins in the British Museum, Volume III: Nerva to Hadrian (London 1976).

RPC: M. Amandry y A., Burnett, Roman Provincial Coinage, Volume III (London 2015).

\section{BiBLIOGRAFÍA}

AmANDRY, P.: "Sur les concours argiens», Études argiennes, suplement VI, 1980, pp. 211-253.

Amandry, P.: "Le bouclier d'Argos", Bulletin de Correspondance Hellenique, 107, 1983, pp. 627-634.

Aurigemma, S.: Villa Adriana. Roma, 1996.

Avagliano, A.: "L'Ares tipo Borghese: Una rilettura", Archeologia Classica, LXII, 2011, pp. 41-76.

Barattolo, A.: "Il tempio di Venere e di Roma: un tempio "greco" nell'urbe", Mitteilungen des deutschen archäologischen Instituts, Römische Abteilung, 85, 1978, pp. 397-410.

Beaujeu, J.: La Religion Romaine a l'Apogée de l'Empire I. La Politique Religieuse des Antonins. Paris, 1955. 
Berger, E.: "Das Urbild des Kriegers aus der Villa Hadriana und die Marathonische Gruppe des Phidias in Delphi", Mitteilungen des deutschen archäologischen Instituts, Römische Abteilung, 65, 1958, pp. 6-19.

Bernand, A.: Les Portes du désert. Recuil des inscriptions grecques d'Antinooupolis, Tentyris, Koptos, Apollonopolis Parva et Apollonopolis Magna. Paris, 1984.

Birley, A.: Hadrian: The Restless Emperor. London. 1997.

Birley, A.: "Los viajes del Emperador Adriano", en Cortés Copete, J. M. \& Muñiz Grijalvo, E. (eds.): Adriano Avgusto. Sevilla, 2004, pp. 57-70.

Blum, G.: "Numismatique d'Antinoos", Journal International d'Archéologie Numismatique, 16, 1914, pp. 33-70.

Bontwright, M. T.: Hadrian and the City of Rome. Princeton, 1987.

Caskey, J. L. \& Amandry, P.: "Investigations at the Heraion of Argos, 1949", Hesperia, 21, 1952, pp. 165-221.

Calandra, E.: Oltre la Grecia: Alle origini del filellenismo di Adriano. Perugia, 1996.

Carandini, A. \& Papi, E.: Adriano. Roma e Atene. Milano, 2019.

Cassatella, A. \& Panella, S.: "Restituzione dell'impianto Adrianeo del Tempio di Venere e Roma", Archeologia laziale, 10, 1990, pp. 52-54.

Curtis, P. \& Vout, C. (eds.): Antinous: The Face of the Antique. Leeds, 2006.

Dietrichson, L.: Antinoos: Eine Kunstarchäologische Untersuchung. Christiania, 1884.

Fabiani, U. \& Fraioli, F.: "Note sull'allineamento del Tempio di Venere e Roma", FastiOnLine documents E research, 193, 2010, pp. 1-10.

Flament, Ch. \& Marchetti, P.: Le monnayage argien d'époque romaine, d'Hadrien à Gallien. Athens, 2011.

Fougères, G.: Mantinée et l'Arcadie orientale. Paris, 1898.

Fusco, U.: "The Sanctuary of Aphrodite and Ares,Paus. 2.25.1, in the Periurban Area of Argos and Temples with a Double Cella in Greece", Tekmeria, 13, 2016, pp. 97-124.

Galimberti, A.: Hadrian e l'ideologia del principato. Roma, 2007.

Galdi, M.: «Et Graeci quidem eum consecraverunt: la creazione del mito di Antinoo", en Cordovana, O. D. \& Galli, M. (eds.): Arte e memoria culturale nell'età della Seconda Sofistica. Catania, 2007, pp. 189-209.

Golden, M.: Sport in the Ancient World from A to Z. London/New York, 2004.

GoRDillo, R.: "Adriano y el calendario imperial de juegos atléticos: propuesta sobre el tercer y cuarto año del ciclo olímpico", Gerión 35/1, 2017, pp. 117-140. 
Gouw, P.: Griekse Atleten in de Romeinse Keizertijd, 31 v. Chr. - 400 n. Chr. Amsterdam, 2009.

Graindor, P.: "Études sur l'éphébie attique sous l'Empire», Musée Belge, 26, 1922, pp. 165-228.

Grenier, J-C.: L'Osiris Antinoos. Montpellier, 2008.

Hartswick, K. J.: "The Ares Borghese Reconsidered", Revue Archéologique, 2, 1990, pp. 227-283.

HøJте, J. M.: "Imperial Visits as Occasion for the Erection of Portrait Statues?", Zeitschrift für Papyrologie und Epigraphik, 133, 2000, pp. 221-235.

Imhoof-Blumer, F. \& Gardner, P.: Ancient Coins Illustrating Lost Masterpieces of Greek Art. A Numismatic Commentary on Pausanias. Chicago, 1964.

JONES, CHR.: "Three New Letters of the Emperor Hadrian", Zeitschrift für Papyrologie und Epigraphik, 161, 2007, pp. 145-156.

Jones, C. P.: New Heroes in Antiquity: From Achilles to Antinoos. Cambridge/MA/London, 2010.

KleINER, D. E. E.: "Second-Century Mythological Portraiture: Mars and Venus", Latumus, 40.3, 1981, pp. 512-544.

KnApP, R. C. \& MAC ISAAC, J. D.: Excavations at Nemea III. The coins. California/Los Angeles/London, 2005.

KNAUER, E. R.: "Mitra and kerykeion. Some reflections on symbolic attributes in the art of the classical period", Archäologischer Anzeiger, 1992, pp. 373-399.

Kousser, R.: "Mythological Group Portraits in Antonine Rome: The Performance of Myth", American Journal of Archaeology, 111.4, 2007, pp. 673-691.

KuHLmann, P.: Religion und Erinnerung: Die Religionpolitik Kaiser Hadrians und ibre Rezeption in der antiken Literatur. Göttingen, 2002.

LAmbert, R.: Beloved and God: The Story of Hadrian and Antinous. New York, 1984.

LE Guen, B.: "Hadrien, l'Empereur philhellène, et la vie agonistique de son temps. À propos d'un livre récent: Hadrian und die dionysischen Künstler. Drei in Alexandria Troas neugefundene Briefe des Kaisers and die Künstler-Vereinigung", Nikephoros, 23, 2010, pp. 205-239.

Lo Monaco, A.: "Adriano in visita agli dèi in Grecia", en Calandra, E. \& Adembri, B. (eds.): Adriano e la Grecia: Studi e ricerche. Milano, 2014, pp. 27-35.

Magnetto, A.: Gli arbitrati interstatali greci II. Dal 337 al 196 a. C. Pisa, 1997.

Mambella, R.: Antinoo: l'ultimo mito dell'antichità nella storia e nell'arte. Milano, 1995. 
Mambella, R.: Antinoo: l'ultimo Ulisside. Pescara, 2000.

Mambella, R.: Antinoo: "un dio malinconico" nella storia e nell'arte. Roma, 2008.

Mari, M.: Al di là dell'Olimpo. Macedoni e grandi santuari nella Grecia dall'età arcaica al primo ellenismo. Athens, 2002.

MARI, M.: "Festa Mobile. Nemea e suoi giochi nella tradizione letteraria e nell'evidenza materiale I: l'età arcaica e classica", Incidenza dell'Antico, 6, 2008, pp. 91-132.

Meyer, H.: Antinoos. Die archäologischen Denkmäler unter Einbeziehung des numismatischen und epigraphischen Materials sowie der literarischen Nachrichten. Ein Beitrag zur Kunst- und Kulturgeschichte der hadrianisch-frühantoninischen Zeit. Münich, 1991.

Miller, S. G.: "Excavations at Nemea 1976”, Hesperia, 46, 1977, pp. 1-26.

Miller, S. G. (ed.): Nemea. A guide to the Site and Museum. California, 1990.

Miller, S. G.: Excavations at Nemea II: The Early Hellenistic Stadium. California, 2001.

Miller, S. G., Knapp, R. C. \& Chamberlain, D.: Excavations at Nemea II. The early bellenistic stadium. California/Los Angeles /London, 2001.

Minakaran-Hiesgen, E.: "Zum "Drieger" in Tivoli", en Winkes, R., Cahn, H. A. \& Simon, E. (eds.): Tainia. Festschrift für Roland Hampe. Mainz am Rhein, 1980, pp. 181-195.

Moesch, V.: "Numeri catalogo 32-39", en Adembri, B. (ed.): Adriano: Architettura e progetto. Milano, 2000, pp. 217-228.

MoretTI, L.: Inscrizioni Agonistiche Greche. Roma, 1953.

Oliver, J.: Marcus Aurelius: Aspects of Civic and Cultural Policy in the East. Athens, 1970.

OpPeR, Th.: Hadrian: Empire and Confict. London, 2008.

Ortega, A.: Odas y Fragmentos: Olimpicas, Píticas, Nemeas, Ístmicas, Fragmentos. Madrid, 1984.

PARlascA, K.: "Antinoos Heros", Chronique d'Égypte, 84/168, 2009, pp. 348356.

PAVESE, C. O.: "Il "Marte" di Villa Adriana: una statua attica di "hoplitodromos", Arte e Documento, 2, 1988, pp. 24-31.

Pensabene, P.: "Mármoles y talleres en la Bética y otras áreas de la Hispania romana", en Vaquerizo, D. \& Murillo, J. F. (eds.): El concepto de lo provincial en el mundo antiguo: Homenaje a la profesora Pilar León Alonso, Vol. II. Córdoba, 2006, pp. 103-142.

Pensabene, P.: "Canopo" di Villa Adriana. Programmi tematici, marmi e officine nell'arredo statuario", ASAtene 87, serie 3, 9, Tomo I, 2009, pp. 381-424. 
Pensabene, P.: "Arredo statuario del Canopo di Villa Adriana", en Ghini, G. (ed.): Lazio e Sabina. 7 Atti del convegno: Settimo incontro di studi sul Lazio e la Sabina, Roma 9-11 mar. 2011, pp. 17-32.

Petzl, G. \& Schwertheim, E.: Hadrian und die Dionysischen Künstler: Drei in Alexandria Troas neugefundene Briefe des Kaisers an die KünstlerVereinigung. Bonn, 2006.

Pironti, G.: "Aphrodite dans le domaine d'Arès: Éléments pour un dialogue entre mythe et culte", Kernos, 18, 2005, pp. 167-184.

Pudill, R.: Antinoos: Münzen und Medaillons. Battenberg, 2014.

RAEDER, J.: Die statuarische Ausstattung der Villa Adriana bei Tivoli. Frankfurt, 1983.

RATHGeBer, G.: "Sur une médaille d'Argos du cabinet de médailles du duc de Gotha", Annali dell'Instituto di Corrispondenza Archeologica, V, 1833, pp. 322-323.

Remijsen, S.: The End of Greek Athletics in Late Antiquity. Cambridge, 2015. RoBert, L.: À travers l'Asie Mineure: poètes et prosateurs, monnaies grecques, voyageurs et géographie. Athens, 1980.

Roux, G.: L'architecture de l'Argolide aux IV et III siecles avant J. C. Paris, 1961.

Stamper, J. W.: The Architecture of Roman Temples: The Republic to the Middle Empire. Cambridge, 2005.

STRASSER, J.-Y.: "La carrière du pancratiaste Markos Aurèlios Dèmostratos Damas", Bulletin de Correspondance Hellenique, 127, 2003, pp. 251299.

STRAsser, J. Y.: "Qu'on fouette les concurrents...": à propos des lettres d'Hadrien retrouvées à Alexandrie de Troade", Revue des Etudes Greques, 123.2, 2010, pp. 582-622.

Thompson, T. W.: Antinoos, The New God: Origen on Miracle and Belief in Third-Century Egypt, en Nicklas T. \& SpITTLER, J. E. (eds.): Credible, Incredible. The Miraculous in the Ancient Mediterranean. Tübingen, 2013, pp. 143-172.

Tomlinson, R. A.: Argos and the Argolid: Fron the end of the Bronze Age to the Roman occupation. London, 1972.

Turcan, R.: "La "Fondation" du Temple de Venus et de Roma", Latomus, 23, 1964, pp. 44-48.

Vermeule, C. C.: "Roman Cult Images on Coins of the Emperor Hadrian, Mars Ultor, Virtus and Mars Victor", Spink E Son Numismatic Circular, 63, 1955, pp. 313-315.

WeBER, W.: Untersuchungen zur Geschichte des Kaisers Hadrianus. Leipzig, 1907.

Wegner, M.: Hadrian, Plotina, Marciana, Matidia, Sabina. Berlin, 1956. 
ROCÍO GORDILLO HERVÁS

LA REPRESENTACIÓN DE ANTINOO Y ADRIANO-ARES/MARTE

EN EL CONTEXTO ARGÓLICO
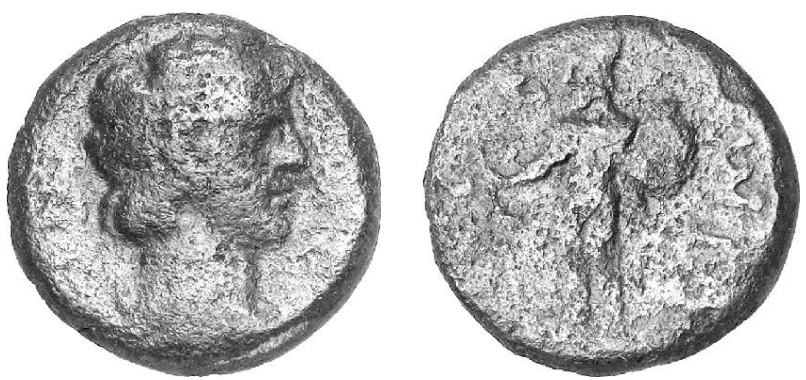

Fig. 1. Moneda de Argos (RPC 3, 390). Copyright: LHS Numismatics Ltd, Zürich, Auction 96, 8-9 May 2006, lot 1188. 
